(C) 2021, The Authors. Published by Elsevier Inc. and Fass Inc. on behalf of the American Dairy Science Association ${ }^{\circledR}$. This is an open access article under the CC BY-NC-ND license (http://creativecommons.org/licenses/by-nc-nd/4.0/).

\title{
Modifiable management practices to improve udder health in dairy cattle during the dry period and early lactation: A scoping review
}

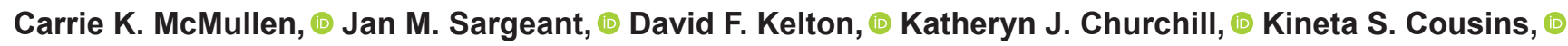 \\ and Charlotte B. Winder* (1) \\ Department of Population Medicine, Ontario Veterinary College, University of Guelph, Guelph, ON, Canada, N1G 2W1
}

\begin{abstract}
The objective of this scoping review was to characterize all available literature on modifiable management practices used during the dry period that have been evaluated for their effects on udder health in dairy cattle during the dry period and the subsequent lactation. Five databases and two conference proceedings were searched for relevant literature. Articles published in or after 1990 were eligible for inclusion. Eligible interventions or exposures were restricted to modifiable management practices; however, antimicrobial and teat sealant products were enumerated but not further characterized, as systematic reviews have been published on this topic. Other modifiable management practices were reported in 229 articles. Nutrition $(\mathrm{n}=79)$, which included ration formulation and delivery $(\mathrm{n}=44)$ and vitamin and mineral additives $(\mathrm{n}=35)$, was the most commonly reported practice, followed by vaccines (n $=40)$ and modification of dry period length $(\mathrm{n}=27)$. Risk of clinical mastitis (CM) was the most commonly reported outcome $(\mathrm{n}=151)$; however, reporting of outcome risk periods varied widely between articles. Cure of existing intramammary infections (IMI) over the dry period $(\mathrm{n}=40)$ and prevention of new IMI over the dry period $(\mathrm{n}=54)$ were most commonly reported with a risk period between calving and $30 \mathrm{~d}$ in milk. Future systematic reviews with meta-analyses could target management practices such as nutrition, vaccines, and dry period length to quantify their effects on improving udder health during the dry period and early lactation. However, the variation in reporting of time at risk for $\mathrm{CM}$ and other outcomes challenges the ability of future synthesis work to inform management decisions on the basis of efficacy to cure or prevent IMI and CM. Consensus on which core outcomes should
\end{abstract}

Received November 4, 2020.

Accepted March 16, 2021.

*Corresponding author: winderc@uoguelph.ca be evaluated in mastitis research and the selection of consistent risk periods for specific outcomes in animal trials is imperative.

Key words: dry cow, management, mastitis, intramammary infection, dry period

\section{INTRODUCTION}

The dry period following lactation represents the time dairy cows are most at risk for developing IMI (Halasa et al., 2009a). The presence of IMI during the dry period also increases the risk of clinical mastitis $(\mathbf{C M})$ in the subsequent lactation, most commonly during the first 30 to 60 DIM (Pantoja et al., 2009). A traditional approach to decrease the impact of IMI and CM on milk quality and quantity in the subsequent lactation is the use of long-acting intramammary antimicrobials at dry-off (DO). However, concern over the prudent use of antimicrobials in agriculture (World Organisation for Animal Health, 2019) has informed the need to assess the efficacy of additional management practices that can be used to protect udder health during the dry period, either in addition to or in place of antimicrobial dry cow products.

Dairy cattle experience some form of management changes when entering the dry period (Zobel et al., 2015). The majority of the published literature regarding management practices that improve udder health around the time of drying off center around intramammary antimicrobials (Dingwell et al., 2003b; Halasa et al., 2009a,b) and teat sealants (Berry and Hillerton, 2002; Halasa et al., 2009a; Rabiee and Lean, 2013). However, other management strategies have been evaluated for their effects on udder health, including method of milk cessation (Dingwell et al., 2003a; Vilar and Rajala-Schultz, 2020) and bedding and housing of dry cows (Dufour et al., 2011). Systematic reviews and meta-analyses have assessed the impact of adjusting dry period length on the risk of CM (van Knegsel et al., 2013) as well as the effects of antimicrobials (Winder et al., 2019a) and teat sealants (Dufour et al., 2019; Winder et al., 2019b) given at DO to prevent IMI and 
mastitis postcalving, and a meta-analysis assessing the effect of DO antimicrobials, teat sealants, and vaccines in nulliparous heifers has been published (Naqvi et al., 2018). Other aspects of dry cow management have also been evaluated for their effects on udder health in multiparous cows, including strategies for cessation of lactation, bedding materials, hygiene of the environment, standing behavior following dry cow therapy, vaccinations, fly control, and nutrition (Green et al., 2007). With increased scrutiny on use of antimicrobials in food animals, a need exists to characterize all literature regarding modifiable management practices of dairy cattle during the dry period that have been evaluated for their influence on udder health.

Scoping review methodology is used to characterize the range of available literature for broad research questions, determine the value of undertaking a systematic literature review, provide a high-level summary of research findings, and identify gaps in existing literature (Arksey and O'Malley, 2005). Currently, no scoping review has characterized literature reporting modifiable management practices that can be implemented at drying off to improve udder health in dairy cattle. Understanding the efficacy of management practices that can be modified during the dry period of lactation is essential to help producers maintain good animal health and milk quality while supporting the prudent use of antimicrobials in agriculture. This scoping review will provide an indication of the feasibility of a systematic literature review and meta-analysis of areas of dry cow management and will identify gaps in existing literature.

The objective of this scoping review was to characterize all available literature on modifiable management practices used during the dry period that have been evaluated for their influence on udder health in dairy cattle, during both the dry period and the subsequent lactation.

\section{MATERIALS AND METHODS}

\section{Protocol and Registration}

A scoping review protocol was published in the online University of Guelph repository and can be accessed at https://atrium.lib.uoguelph.ca/xmlui/bitstream/ handle/10214/17788/McMullenProtocol_DryCowMgm _PROTOCOL.pdf? sequence $=1$ \&isAllowed $=y . \quad$ Manuscript preparation followed the reporting guidelines of the Preferred Reporting Items for Systematic Reviews and Meta-Analyses extension for scoping reviews (Tricco et al., 2018). This scoping review followed the framework proposed by Arksey and O'Malley (2005). There were no protocol deviations in this scoping review.

\section{Eligibility Criteria}

Eligible articles were published in English and reported results of analytic observational studies, controlled trials, or challenge trials. Articles had to be $\geq 500$ words and published within the last 30 years (i.e., January 1, 1990, to February 18, 2020). Genetic selection has produced dairy cows that are capable of superior milk production, compared with their historical ancestors (USDA, 2004; Dobson et al., 2007; Barkema et al., 2015), and significant advances in disease prevention have been achieved over the last 30 years (LeBlanc et al., 2006). Therefore, restricting the publication date ensured that this scoping review included data that were temporally relevant.

A population of dairy cattle at cessation of lactation, and an intervention or exposure to any DO modifiable management practice with the goal of improving udder health were required for an article to be eligible. Nonmodifiable management practices were excluded from this review (i.e., breed, parity, season of DO). Analytical studies had to provide comparison of the intervention or exposure to at least one other different intervention, a different level of the given intervention or exposure, or a nontreated control group or placebo. Finally, eligible articles had to describe one of the following udder health outcomes in the title or abstract: risk of CM at any period postcalving, prevention of new IMI during the dry period, cure of existing IMI during the dry period, or prevalence of IMI at any period postcalving. Prevention of new IMI and cure of existing IMI were eligible outcomes only when milk samples were taken at least at DO and postcalving for determination of IMI status. No restriction was placed on how IMI was defined, which could have included but was not limited to bacterial culture, SCC, electrical conductivity, or $\mathrm{N}$-acetyl-beta-D-glucosaminidase (NAGase).

\section{Information Sources}

The search was completed by CKM on February 18, 2020, by searching 5 databases for relevant literature: Medline (via OvidSP), CAB Abstracts (via CAB Interface), Science Citation Index (via Web of Science), Scopus, and Agricola (via Proquest). CKM also handsearched the table of contents from 1990 to 2020 of the World Association for Buiatrics Conference Proceedings and the National Mastitis Council Conference Proceedings. Contact with study authors was not conducted.

\section{Search}

The full-electronic search string was developed in CAB Abstracts (via CAB Interface; Table 1). The 
Table 1. Search strategy to identify relevant articles for the scoping review characterizing modifiable management practices implemented at drying off to improve udder health in dairy cattle, published between 1990 to 2020, conducted in CAB Abstracts (via CABI) on February 18, 2020

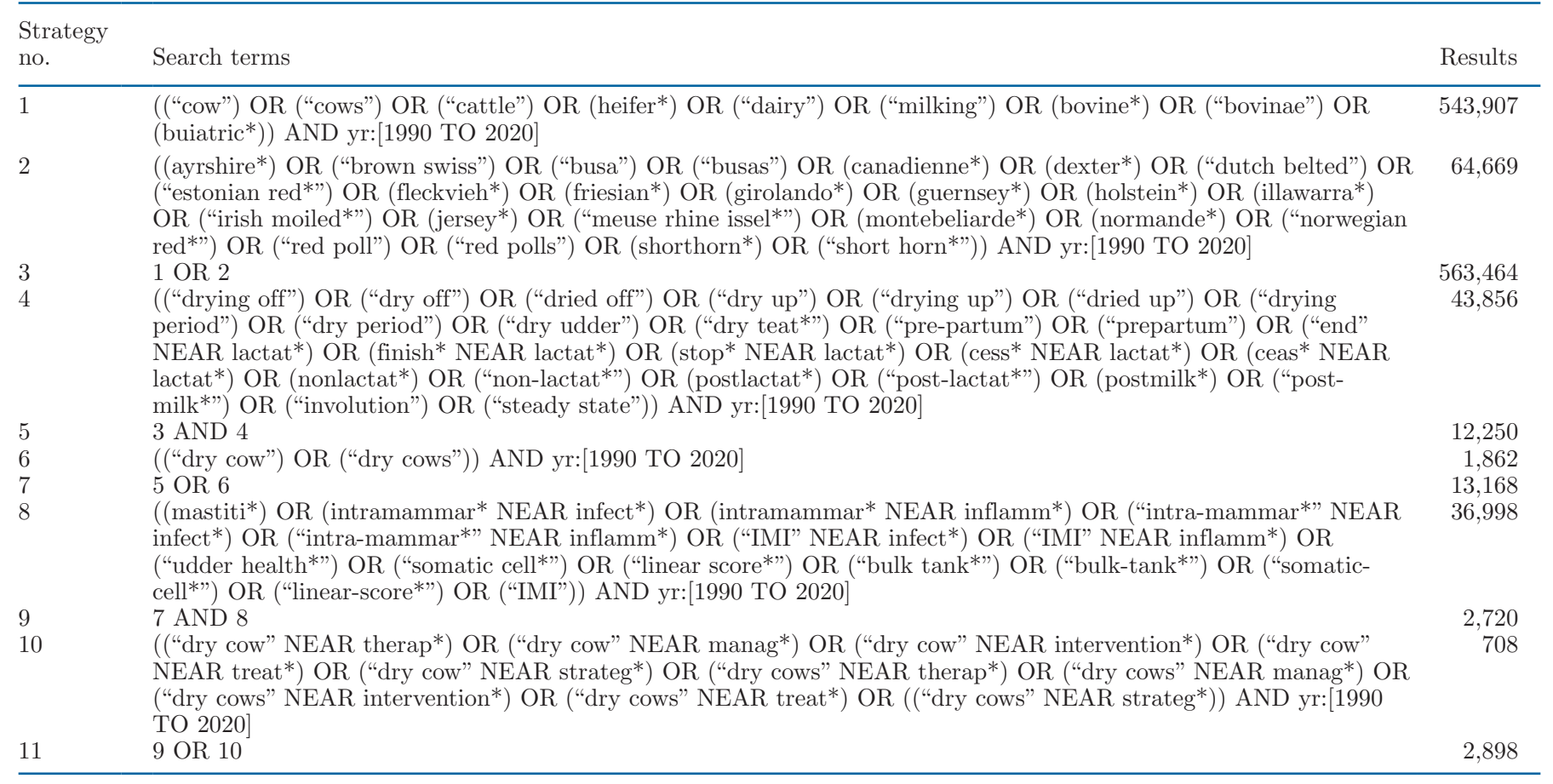

search was restricted to publication year from 1990 to 2020. The search was validated by checking inclusion of 15 articles preselected by DFK (Table 2); all articles were detected by the search strategy. Search results were downloaded into EndNote (EndNote X7, Clarivate Analytics) and then uploaded into DistillerSR (Evidence Partners Inc.) and deduplicated before the screening process.

\section{Selecting Sources of Evidence}

Study selection and data extraction were performed in DistillerSR. Two levels of screening were conducted by CKM, CBW, KJC, and KSC. The title and abstract pretest involved screening 100 articles for eligibility, followed by a consensus meeting to ensure reviewer consistency and clarity of the screening questions. Reviewers independently in duplicate screened the title and abstract of articles identified by the search using 4 primary screening questions. (1) Is a modifiable dry period management practice in dairy cattle reported in the title or abstract? (2) Is a relevant udder health outcome described in the title or abstract? (3) Is the title or abstract available in English? (4) Is an analytic primary research study described in the title or abstract? Response selection included yes, no, or unclear, and a response of no from 2 reviewers to any of the questions resulted in exclusion of that reference. All disagreements were resolved by consensus. The full-text pretest involved screening 10 full-text articles for eligibility, followed by a consensus meeting. The following 5 secondary screening questions were used for full-text screening. (1) Is the study available in English? (2) Is this an analytic primary research study? (3) Is a population of dairy cattle after their first or subsequent lactation reported within the article? (4) Was the modifiable management practice implemented at drying off? (5) Is a relevant udder health outcome reported in the article? Possible response options were yes or no, where an answer of no selected by 2 reviewers resulted in exclusion of that record. Agreement was at the question level, and a third member of the review team was consulted for conflict mediation if consensus could not be reached.

\section{Data Charting Process}

Data extraction was completed independently in duplicate by CKM, CBW, KJC, and KSC using a structured pretested form created in DistillerSR. The form was pilot tested using 5 articles by all reviewers to ensure consistency and clarity of the questions. Thereafter, disagreements were resolved by consensus. 
Table 2. Article title and author information for 15 relevant journal articles to check for inclusion in the search to validate the search strategy for the scoping review characterizing modifiable management practices implemented at drying off to improve udder health in dairy cattle; all articles were identified by the search

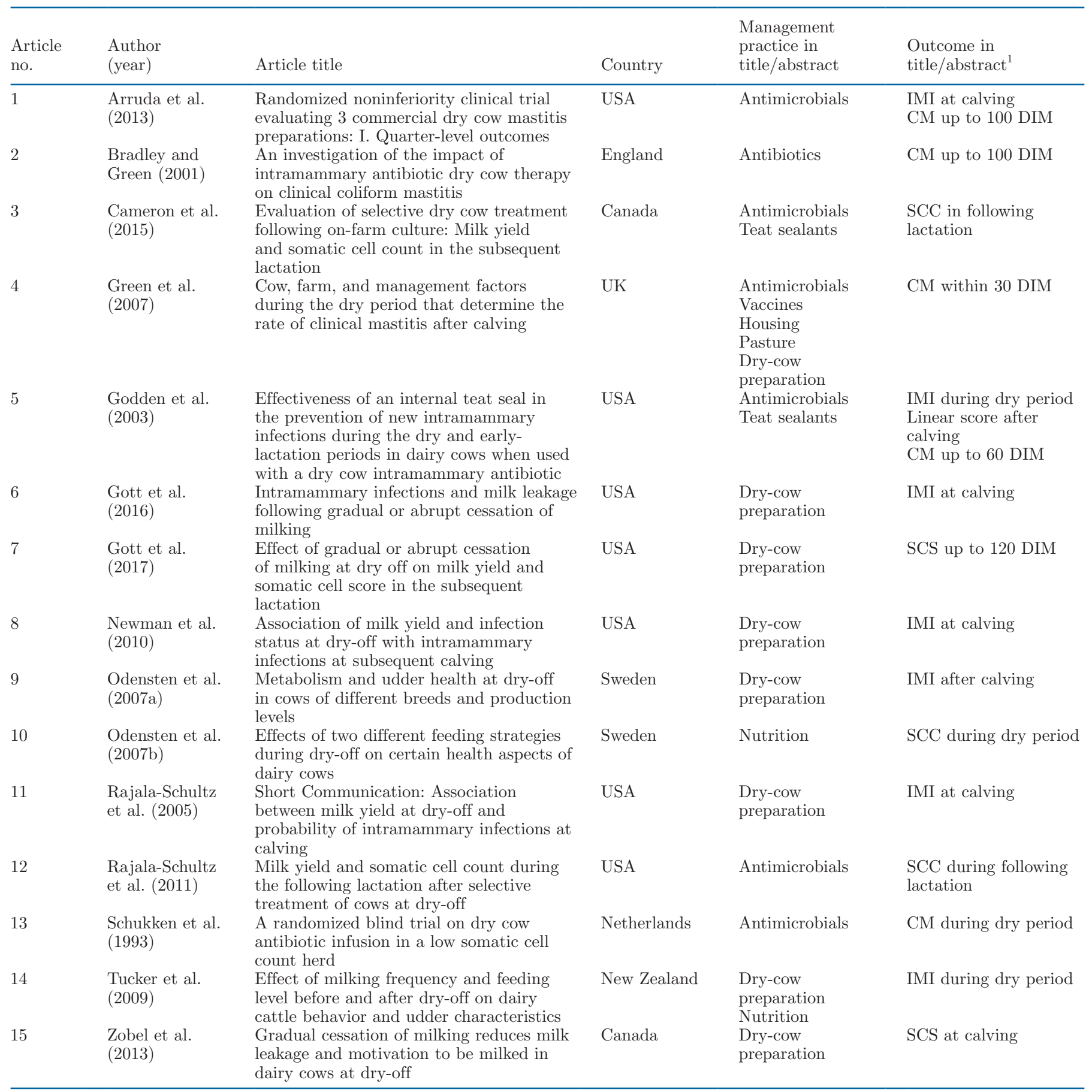

${ }^{1} \mathrm{CM}=$ clinical mastitis.

\section{Data Items}

Study Characteristics. Study-level data included year of publication, year of study conduct, country of study conduct, study design, study objectives, farm or herd type (research or university dairy, or commercial dairy), and breed.

Intervention, Comparators, and Exposures. Intervention, comparator, and exposure data included definition and type of management practice, interven- 
tion unit (farm, herd, cow, or quarter), implementation strategy of intervention or exposure, and implementation of the comparator.

Outcomes. Eligible outcomes for inclusion in the review were as follows: risk of CM (author-defined risk period), cure of existing IMI from DO to calving, prevention of new IMI from DO to calving, and prevalence of IMI (author-defined risk period).

Authors had to report that milk samples were collected at drying off and at calving, or at another point postcalving, for IMI determination in order for cure of existing IMI and prevention of new IMI to be eligible outcomes. These samples are later referred to as cure and prevention of IMI over the dry period in this manuscript, but authors could have included milk samplings that extended into lactation. In addition, risk period evaluation for CM and prevalence of IMI could be author-defined and could extend throughout the next lactation, as long as the risk period was not defined as the incidence or prevalence of disease only over the entire lactation. This decision was made to include studies reporting a risk period that was not so long, such that the influence of factors other than the dry period management practice became more substantial reasons for a case or non-case (i.e., contaminated milking equipment). Somatic cell count as a continuous measure of udder health was not reported in the protocol; however, SCC is a very common test to identify potential IMI and thus was included as an additional outcome in this scoping review. Articles that mentioned only antimicrobials or teat sealant interventions were enumerated but not further characterized, as they have been included in previous systematic literature reviews and meta-analyses on the efficacy of these products to improve udder health during the dry period (Dufour et al., 2019; Winder et al., 2019a,b). Other modifiable management strategies reported within an article with antimicrobial or teat sealant products remained eligible for inclusion.

\section{Synthesis of Results}

Metrics such as mode and range were used to describe the outcome risk periods, to present the most common risk period value and the variation in risk periods reported in the published literature included in this scoping review.

\section{RESULTS}

\section{Selection of Sources of Evidence}

Results of the search and the flow of study inclusions and exclusions are presented in Figure 1. Following both levels of relevance screening, 420 articles were included in the quantitative summary: antimicrobials and teat sealants alone were assessed in 74 articles, antimicrobials alone in 108 articles, teat sealants alone in 9 articles, and other modifiable management practices (with or without comparison to antimicrobials or teat sealants) in 229 articles. Only the 229 articles that included the report of modifiable management practices that were not antimicrobials or teat sealants were further described in this scoping review.

\section{Characteristics of Sources of Evidence}

Articles published in or after 1990 were eligible for inclusion, with year of publication ranging from 1990 to 2020. The majority of studies were conducted in the United States (84/229; 36.7\%), Canada (19/229; 8.3\%), and the United Kingdom (13/229; 5.7\%). Although controlled trials were the most common study design identified $(174 / 229 ; 76.0 \%)$, challenge trials $(22 / 229 ; 9.6 \%)$, cohort studies $(18 / 229 ; 7.9 \%)$, and cross-sectional studies $(15 / 229 ; 6.6 \%)$ were also identified by our review team. A commercial herd type was reported in half of the articles $(113 / 229 ; 49.4 \%)$, followed by research or university herds $(70 / 229 ; 30.6 \%)$, and both herd types were reported in a smaller number of articles (5/229; $2.2 \%$ ). Herd type was not reported in 41 articles. Breed of cattle included in each article was mainly Holstein $(106 / 229 ; 46.3 \%)$ and multiple breeds $(35 / 229 ; 15.3 \%)$, followed by crossbreeds $(7 / 229 ; 3.1 \%)$, Jersey $(5 / 229$; $2.2 \%)$, and other breeds $(6 / 229 ; 2.6 \%)$. Breed was not reported in 70 articles.

\section{Synthesis of Results}

Vaccines. The effects of vaccination on eligible udder health outcomes were assessed in 40 articles, of which 20 were controlled trials, 17 were challenge trials, and 3 were observational studies (Supplemental Table S1; https://doi.org/10.5683/SP2/TJVYOZ; McMullen et al., 2021). Within controlled trials, the 2 most common types of vaccine regimen were Escherichia coli J5 vaccine $(9 / 20)$ and Startvac (a vaccine for $E$. coli, coagulase-negative staphylococci, and Staphylococcus aureus; $7 / 20$ ), followed by $S$. aureus vaccination $(3 / 20)$ and a vaccine for coliforms $(1 / 20)$. Comparison to an untreated control group was made in over half of controlled trials $(12 / 20)$ and to a placebo product in 4 trials. The $E$. coli J5 vaccine was administered in the majority of challenge trials $(11 / 17)$, with Streptococcus uberis immunization reported in 2 challenge trials. Most comparators in challenge trials were untreated control $(14 / 17)$, a different vaccination $(10 / 17)$, or placebo vaccination (3/17). Intramuscular Startvac and a 
leptospirosis vaccine for herds at pasture were assessed for their effect on udder health in 3 observational studies. For all vaccination studies, CM was reported in the majority of articles $(36 / 40)$, with a range in risk period from DO to 240 DIM (mode: 90 DIM). Cure of existing IMI over the dry period was reported in 6 articles, prevention of new IMI over the dry period in 9 articles, and prevalence of IMI over the dry period in 16 articles. Somatic cell count was measured in 30 articles from DO to 240 DIM.
Nonantimicrobial Intramammary Products. Nonantimicrobial intramammary products were reported in 12 articles, of which 10 were controlled trials and 2 were challenge trials (Supplemental Table S2; https://doi.org/10.5683/SP2/TJVYOZ; McMullen et al., 2021). Products reported included IL-2 (3/12), Phyto-Mast or Cinnatube or the combination thereof $(3 / 12)$, bovine lactoferrin $(2 / 12)$, lysostaphin $(2 / 12)$, ozone-containing foam $(1 / 12)$, and casein hydrolysate $(1 / 12)$. Clinical mastitis was reported as an outcome

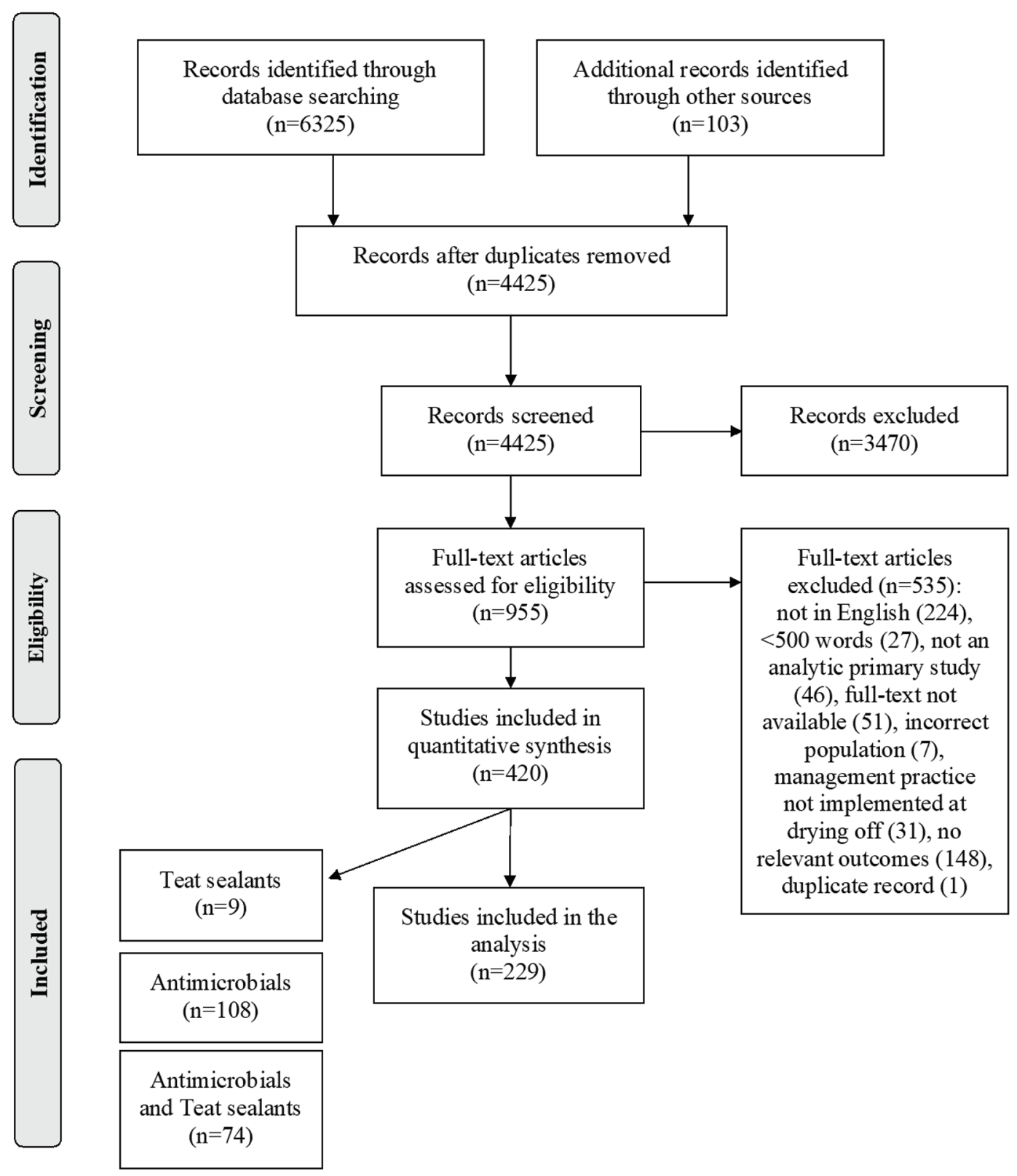

Figure 1. Preferred Reporting Items for Systematic Reviews and Meta-Analyses (PRISMA) flow diagram of studies included in the scoping review characterizing modifiable management practices implemented at drying off to improve udder health in dairy cattle (Moher et al., 2009). 
in 11 articles, with a risk period range from DO to 42 DIM (mode: at calving). Cure of existing IMI over the dry period was reported in 8 articles, prevention of new IMI over the dry period in 5 articles, and prevalence of IMI over the dry period in 5 articles. Somatic cell count was measured in 9 articles from DO to 90 DIM. Intramuscular injection of nonantimicrobial products was reported in 2 additional controlled trials, of which recombinant bovine granulocyte stimulating factor was administered in one trial and Propionibacterium acnes immunostimulatory product in the other (Supplemental Table S2; https://doi.org/10.5683/SP2/TJVYOZ; McMullen et al., 2021).

Vitamin and Mineral Injections. Vitamin and mineral products were injected intramuscularly or subcutaneously in 14 articles, all of which were controlled trials (Supplemental Table S3; https://doi.org/10 .5683/SP2/TJVYOZ; McMullen et al., 2021). Vitamin $\mathrm{E}$ and selenium products were most commonly reported $(9 / 14)$. Untreated control was used as a comparator in 10 trials and a placebo product in 4 trials. Clinical mastitis was reported in 8 trials, with a range in risk period from 30 to 200 DIM (mode: 30 DIM). Cure of existing IMI over the dry period and prevention of new IMI over the dry period were each reported in 3 trials, prevalence of IMI over the dry period in 5 trials, and SCC in 6 trials from calving through the entire lactation.

Nutrition: Vitamin and Mineral Feed Additives. Vitamin and mineral feed additives were reported in 35 articles, of which 30 were controlled trials, 1 was a challenge trial, and 4 were observational studies (Supplemental Table S4; https://doi.org/10.5683/ SP2/TJVYOZ; McMullen et al., 2021). Vitamin E, or a combination of vitamin $\mathrm{E}$ and other minerals, was the most commonly evaluated vitamin as an additive in transition cow diets for an effect on udder health $(13 / 35)$, followed by selenium combination products $(7 / 35)$ and calcium combination products $(4 / 35)$. Untreated control was the most common comparator in controlled trials $(24 / 30)$. Clinical mastitis was reported in 22 articles, with a risk period range of DO to 300 DIM (mode: 30 DIM). Cure of existing IMI over the dry period was reported in 3 articles, prevention of new IMI over the dry period was reported in 7 articles, and prevalence of IMI over the dry period was reported in 7 articles. Somatic cell count was reported in 25 articles from DO to 240 DIM.

Nutrition: Ration Formulation and Delivery. Ration formulation and delivery were the most common type of dry cow management practices reported in the articles included in this scoping review $(\mathrm{n}=44)$, of which 39 were controlled trials, 1 was a challenge trial, and 4 were observational studies (Supplemental Table
S5; https://doi.org/10.5683/SP2/TJVYOZ; McMullen et al., 2021). Variation in the length of time close-up and far-off rations were offered was evaluated in 7 articles. OmniGen-AF (Phibro), a product that contains microbials, vitamins, and aluminosilicates, was evaluated for its effect on udder health in 5 articles. Changes in plane of nutrition, such as a decreased concentrate level, restricted feeding at pasture, and variation in protein supplements, were evaluated in 12 articles. Probiotic, microbial, or yeast supplements in transition cow diets were evaluated in 6 articles. Clinical mastitis was reported in 26 articles, with a range in risk period of calving to 308 DIM (mode: 30 and 150 DIM). Cure of existing IMI over the dry period was reported in 2 articles, and prevention of new IMI over the dry period and prevalence of IMI over the dry period were reported in 8 articles. Somatic cell count was measured in the majority of articles (37/44) from DO to 308 DIM.

Dry Period Length. The effect of dry period length on a relevant udder health outcome was reported in 27 articles, of which 17 were controlled trials and 10 were observational studies (Supplemental Table S6; https: //doi.org/10.5683/SP2/TJVYOZ; McMullen et al., 2021). Length of dry period ranged from 0 to $250 \mathrm{~d}$. In controlled trials, the most common dry period length comparator groups were $30 \mathrm{~d}$ and $60 \mathrm{~d}$ (10/17). Most authors were interested in comparison of a conventional dry period length (55-60 d; 13/27) against a shorter dry period length (30-40 d; 14/27), or complete omission of the dry period $(0 \mathrm{~d} ; 10 / 27)$. Clinical mastitis was reported in 16/27 articles, with a range in the risk period from DO to 308 DIM (mode: 90 DIM). Cure of existing IMI over the dry period was reported in $4 / 27$ articles, prevention of new IMI over the dry period in $5 / 27$, and prevalence of IMI over the dry period in $5 / 27$. Somatic cell counts were measured in $23 / 27$ articles from DO to 308 DIM. Additionally, the authors of 7 controlled trials that investigated the efficacy of antimicrobial or teat sealant products also included dry period length as a covariate in regression modeling (Supplemental Table S7; https://doi.org/10.5683/SP2/TJVYOZ; McMullen et al., 2021). The authors of 2 observational studies also reported DIM at drying off or dry period length as a covariate in the model.

Housing, Bedding, Pasture. Housing, pasture, and bedding management were reported in 12 articles, of which 5 were controlled trials and 7 were observational studies (Supplemental Table S8; https://doi.org/ 10.5683/SP2/TJVYOZ; McMullen et al., 2021). The evaluation of tiestall versus freestall on udder health outcomes was reported in 4 articles, indoor stall housing or loose housing was reported in 3 articles, and cows at pasture were reported in 4 articles. Bed or barn 
cleaning routines were reported in 5 articles, and type of bedding was reported in 7 articles, which included sand, straw, wood chip, compost-bedded packs, and mattresses. Other housing management strategies evaluated for their effects on udder health included stall drainage, pasture grazing policies, stall design so that at least $90 \%$ of cows can lie correctly, and access to a housed lying area for cattle at pasture. Clinical mastitis was reported in 10 articles, with a risk period range of calving to 150 DIM (mode: 30 DIM). Cure of existing IMI over the dry period and prevention of new IMI over the dry period were reported in the same 2 articles, prevalence of IMI over the dry period was reported in 4 articles, and SCC was measured in 7 articles from DO to 113 DIM.

Milking Frequency Before Drying Off. Milking frequency before drying off was evaluated in 16 articles, of which 13 were controlled trials and 3 were observational studies (Supplemental Table S9; https://doi.org/ 10.5683/SP2/TJVYOZ; McMullen et al., 2021). Abrupt cessation of lactation (milking cows twice daily until drying off) was compared with gradual or intermittent cessation of lactation (lessening the number of times a cow is milked before drying off) in almost all articles $(15 / 16)$. Gradual or intermittent cessation of lactation was most often defined as a milking frequency change in the last week of lactation $(10 / 16)$, between $14 \mathrm{~d}$ pre-dry to $3 \mathrm{~d}$ pre-dry in the majority of other studies $(5 / 16)$, and report of assessing milk yield records within the last 60 DIM was used in 1 observational study. Clinical mastitis was reported in 4 articles, with a range in risk period from DO to 90 DIM. Cure of existing IMI over the dry period was reported in 4 articles, prevention of new IMI over the dry period was reported in 3 articles, and prevalence of IMI over the dry period was reported in 10 articles. Somatic cell count was reported in 8 articles from DO to 120 DIM.

Reduced Milk Yield at Drying Off. Milk yield at drying off was reported in 9 articles, 2 of which were controlled trials and 7 of which were observational studies (Supplemental Table S10; https://doi.org/10.5683/ SP2/TJVYOZ; McMullen et al., 2021). Milk yield was defined as low, medium, or high in one controlled trial, whereas milk yield at DO $>115 \mathrm{~kg}$ was reported as a risk factor for IMI in the other controlled trial. Milk yield was defined using cut-points in 3 observational studies. Clinical mastitis was reported in 3 articles, with a risk period range from DO to 60 DIM. Cure of existing IMI over the dry period was reported in 1 article, prevention of new IMI over the dry period was reported in 3 articles, and prevalence of IMI over the dry period was reported in 5 articles. Somatic cell count was reported in 3 articles from DO to 30 DIM. The authors of 4 additional controlled trials included milk yield at drying off as a covariate in regression modeling to control for its effect on udder health (Supplemental Table S11; https://doi.org/10.5683/SP2/TJVYOZ; McMullen et al., 2021).

Other Management. Bovine somatotropin is a growth hormone approved for use in dairy cattle to increase milk production (FDA, 2020). Bovine somatotropin was allocated to cows during the dry period in 5 trials to assess its influence on udder health outcomes, via either intramuscular or subcutaneous injections (Supplemental Table S12; https://doi.org/10.5683/ SP2/TJVYOZ; McMullen et al., 2021). Whole-herd concurrent treatment with bovine somatotropin during the dry period was reported in a small number of articles included in this scoping review (4/229). Additional management strategies of interest are reported in Supplemental Table S13 (https://doi.org/10.5683/ SP2/TJVYOZ; McMullen et al., 2021).

Risk of CM was reported as an outcome in over half of the articles identified $(151 / 229 ; 65.9 \%)$, including a corresponding definition in 93 articles as the presence of visible signs, abnormal milk, or systemic illness. A risk period for observation of $\mathrm{CM}$ was reported for the majority of these articles $(137 / 151 ; 90.7 \%)$; however, this ranged from DO through the entire subsequent lactation (Figure 2). The most common maximum numbers of days in milk for which authors evaluated the risk of $\mathrm{CM}$ were $30(19 / 137 ; 13.9 \%), 60(12 / 137$; 8.8\%), 90 (10/137; 7.3\%), and 100 DIM (10/137; 7.3\%).

Cure of existing IMI was reported in 40 articles, of which 35 provided a definition used to classify cows with an existing infection at drying off or over the dry period that cured postcalving. The majority of articles determined cure of IMI through bacteriologic cultures $(30 / 35 ; 85.7 \%)$, which is the method recommended by the National Mastitis Council for determining the presence of subclinical mastitis (NMC, 2012). The remainder used SCC as a proxy for infection status $(5 / 35 ; 14.3 \%)$, defined as SCC $\geq 200,000$ cells $/ \mathrm{mL}$ in 3 of these articles, $\mathrm{SCC} \geq 250,000$ cells $/ \mathrm{mL}$ in 1 article, and no reported cut-point in 1 article. The risk period for measuring cure of existing IMI was not reported in 3 articles, but those that did report a risk period ranged from DO to 130 DIM, most commonly between a maximum of calving and 30 DIM (29/37; 78.4\%).

Prevention of new IMI was reported in 54 articles, of which 50 provided a definition. Most authors defined presence of a new IMI using bacteriological culture $(44 / 50 ; 88.0 \%)$ for quarters negative at drying off but presented with an infection postcalving, Somatic cell count was used as a proxy for infection status in 5 articles, and a modified California Mastitis Test was used 
to define infection status in 1 article. Somatic cell count $\geq 200,000$ cells $/ \mathrm{mL}$ was the cut-point used to define the presence of an infection in 3 articles, and SCC $\geq 250,000$ cells $/ \mathrm{mL}$ was the cut-point used in 1 . The risk period for new IMI was reported in 52 articles, of which IMI was measured between calving and a maximum of 7 DIM in almost half of articles $(23 / 52 ; 44.2 \%)$. Further, new IMI outcome was measured between calving and a maximum of 30 DIM in the majority of articles (40/52; $76.9 \%$ ), with a range in risk period measurement of calving to 240 DIM.

Prevalence of IMI, which refers to IMI that authors reported were measured once over a defined time period, was the most commonly reported metric for

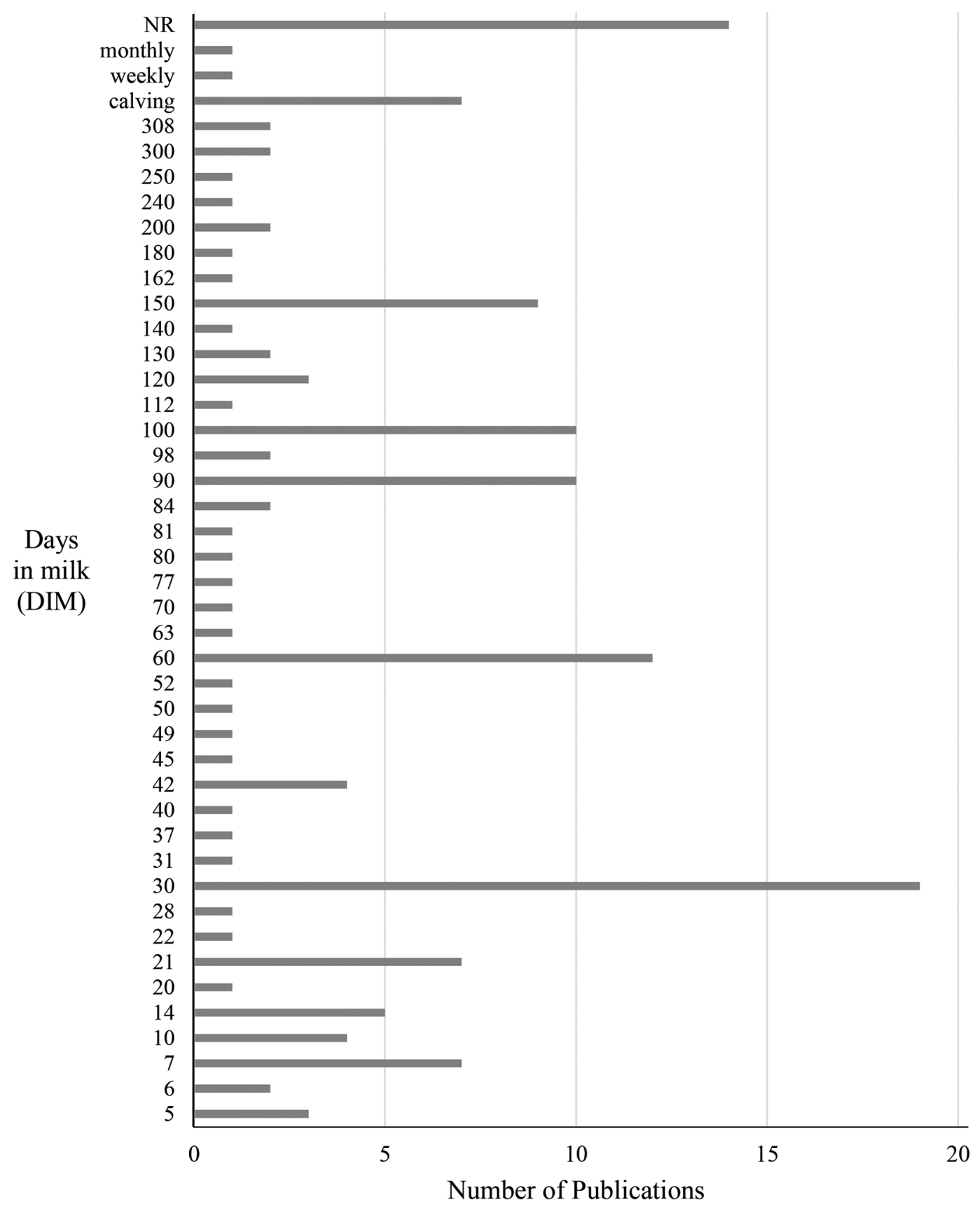

Figure 2. Number of publications that reported clinical mastitis outcomes $(\mathrm{n}=151)$ in the scoping review characterizing modifiable management practices implemented at drying off to improve udder health in dairy cattle, ordered by number of publications per risk period (DIM) evaluated in the study. NR $=$ not reported. 
IMI $(72 / 229 ; 31.4 \%)$. This differs from articles that measured cure of IMI over the dry period and prevention of new IMI over the dry period, because both of these outcomes required at least 2 measurements to determine the incidence of an IMI from DO to calving. Somatic cell count was used to define infection status in 8 articles (8/72) and SCC plus bacteriology in 5 articles, and the remainder performed bacteriologic analysis of milk samples to define infection status $(59 / 72)$. The risk period for measurement of prevalence of IMI ranged from DO to 270 DIM, with a maximum risk period between calving to 30 DIM reported in most articles $(40 / 72 ; 55.6 \%)$. A risk period of $\geq 100$ DIM was reported in 10 articles.

Although few studies reported use of SCC in determination of IMI, SCC was the most commonly reported outcome measure $(\mathrm{n}=161)$, reported as a continuous measure in the majority of articles $(155 / 161)$ or as an elevated SCC (6/161) in the remainder. Transformation of SCC to somatic cell score or linear score was reported in 24 articles $(24 / 161 ; 14.9 \%)$. Maximum risk period measurements for SCC between calving and 30 DIM were reported in one-third of articles (48/161; $29.8 \%)$ and $\geq 100$ DIM in $38 / 161$ articles (23.6\%).

\section{DISCUSSION}

\section{Summary of Evidence}

Using a systematic approach, we characterized dry cow management strategies that can be used in addition to or in replacement of antimicrobials, to aid in the prudent use of antimicrobials in dairy production. We classified management practices into 10 groups: dry period length; vaccines; nonantimicrobial intramammary or intramuscular products; vitamins and minerals (intramuscular); housing, bedding, and pasture management; nutrition, which included ration formulation and delivery and vitamin and mineral feed additives; milking frequency; reduced milk yield at DO; and other.

Substantial literature assessed vaccines $(\mathrm{n}=40)$, nutrition $(\mathrm{n}=79)$, and dry period length $(\mathrm{n}=27)$, which indicates that systematic reviews and metaanalyses may be feasible to quantify their effect on IMI and CM. Naqvi et al. (2018) recently published a systematic review and meta-analysis on the effectiveness of precalving treatment on postcalving udder health in nulliparous dairy heifers, which included mastitis vaccination. Extending this research to populations of multiparous dairy cows would be beneficial to the mastitis research community. Additionally, a recently published meta-analysis assessed the effects of vitamin $\mathrm{E}$ and vitamin $\mathrm{E}$ with selenium adjuvants on SCC in milk (Moghimi-Kandelousi et al., 2020), but future work could include other vitamin and mineral products such as $\beta$-carotene and vitamin A. Santos et al. (2019) conducted a meta-analysis on the effect of a prepartum DCAD on production performance and health of dairy cattle, by means of altering the mineral composition of diets, and found that less than half of included studies reported the effect of DCAD on mastitis. Additionally, Lean et al. (2019) noted that mastitis was not well reported in trials evaluating $\mathrm{DCAD}$, and more studies that report this outcome will increase the precision of future meta-analyses. A future directive for meta-analyses could be to assess the effect of prepartum DCAD on SCC postpartum, as SCC is a commonly reported measure of udder health. Lastly, van Knegsel et al. (2013) conducted a meta-analysis to assess the effect of shortening or omitting the dry period on the incidence of $\mathrm{CM}$ and found variation between studies and variation in disease definitions. An updated systematic review and meta-analysis could indicate whether the consistency between studies for measurement of mastitis in relation to dry period length and mastitis disease definitions has improved. The assessment of the effect of these modifiable management strategies on IMI or SCC during the dry period and postcalving through systematic literature reviews and meta-analyses may be feasible additions to mastitis research.

The majority of articles included in this scoping review were controlled trials $(\mathrm{n}=174)$, which, when allocation to treatment group is randomized, provide the highest evidentiary value for assessing the efficacy of a modifiable intervention under field conditions (O'Connor et al., 2010; Sargeant et al., 2010). Observational studies are useful for exploring risk factors for disease and comparing the effects of management strategies that may be difficult to artificially implement (i.e., housing and stall design or pasture grazing), on udder health outcomes (Sargeant et al., 2016). However, the lack of control of allocation of cows to exposure groups and differential management of exposure groups can lead to biased results. Additionally, challenge trials, like randomized controlled trials, allow trialists to randomly allocate cows to interventions, blind treatment staff or outcome assessors, and maintain equal management of intervention groups, but lack external generalizability (Shirley and McArthur, 2011). Systematic reviews and meta-analyses that include randomized controlled trials provide the highest level of evidence of the efficacy of interventions under field conditions (Sargeant and O'Connor, 2014), and the randomized allocation of participants to treatment groups reduces the potential for selection bias (O'Connor and Sargeant, 2014). However, for com- 
parative efficacy meta-analyses, it may be warranted to include observational studies for areas of veterinary research for which relatively few randomized controlled trials exist, but meta-analysts need to be aware of the potential biases that the inclusion of observational studies can have on the summary effect size (O'Connor and Sargeant, 2014). Therefore, the large proportion of controlled trials included in this scoping review could warrant the exclusion of observational studies from future synthesis work, but for areas of research that are mainly composed of observational studies, such as housing, pasture, and bedding management and decreased milk yield at DO, remain to provide valuable information about the effect modifiable management strategies have on udder health outcomes.

Lastly, we aimed to quantify the number of articles that investigated each management practice in relation to relevant udder health outcomes. Somatic cell count as a continuous metric was the most common measure used to identify udder health issues during lactation, followed by prevalence of IMI during the subsequent lactation. The risk of CM was another commonly investigated outcome, more so than cure or prevention of IMI. Most risk periods for each outcome were defined to a maximum of 30,60 , or 90 DIM; however, we identified discrepancies in author-defined risk periods.

\section{Limitations of the Body of Evidence}

Risk period measurement ranged from DO through the entire lactation for CM, cure of existing IMI, prevention of new IMI, and prevalence of IMI. This variation becomes a problem in further systematic reviews and meta-analyses that require consistent definitions of eligible outcomes and length of follow-up so that data can be meaningfully synthesized and interpreted (Liberati et al., 2009). If we cannot compare the results of multiple studies due to this variation in reporting of outcomes and follow-up periods, then we cannot form a solid evidence base for decision-making (Sargeant et al., 2019). Consensus on one or more risk periods to evaluate CM and IMI outcomes in mastitis research, in addition to other investigator-determined outcomes, would enable the formation of a solid evidence base for decision-making related to udder health. Appropriate follow-up periods need to be long enough to evaluate the effect of a dry period management strategy on CM, but not so long that the influence of factors other than the dry cow management practice become more substantial reasons for a case or non-case.

Evidence exists suggesting optimal thresholds and risk periods for determination of subclinical and clini- cal mastitis. Sargeant et al. (2001) found that optimal sensitivity and specificity for the ability to detect an IMI using an SCC threshold of 100,000 cells/mL was at 5 DIM. A California Mastitis Test using a reaction greater than zero had the highest sensitivity and specificity at 3 or 4 DIM (Sargeant et al., 2001; Dingwell et al., 2002). There is also variability in the literature related to definitions of risk periods for CM (Bradley and Green, 2000; Pantoja et al., 2009; Down et al., 2016). The association between dry period management and first case of CM beyond 90, 100, or 150 DIM is questionable; thus, trialists are urged to provide reasoning for choice of follow-up period. In human healthcare literature, researchers in some areas have developed core outcome measures recommended to be used as a minimum outcome set for all trials in specific topic areas (Kirkham et al., 2019). Such an approach, undertaken by expert consensus of mastitis researchers, could provide consistency in the literature for comparing among studies while allowing flexibility for individual researchers to include additional outcomes of interest.

Further, the majority of articles used bacteriologic culture as the definition for presence of an IMI; cultures are useful measurements when appropriate guidelines are followed, such as the National Mastitis Council guidelines for collecting milk samples (NMC, 2004). A series of studies by Dohoo et al. (2011a,b) evaluated 1 versus 2 samples for culture on the basis of sensitivity and specificity for determining infection status. Compared with the gold-standard test (a positive culture on 2 of 3 consecutive samples), these methods performed adequately. Some articles in our scoping review evaluated 1 sample to determine infection status postcalving (Dingwell et al., 2003a; Mullen et al., 2014), whereas others defined cure of quarters based on the results of 3 or 4 cultures (Middleton and Fox, 1999; Church et al., 2008; Leitner et al., 2011). Likewise, determination of new IMI postcalving was evaluated using at least 2 samples (Berry and Hillerton, 2007; Church et al., 2008; Leitner et al., 2011). The use of SCC to determine subclinical infection status was reported in only a few articles, and although SCC is an important indicator of IMI (Lam et al., 2009), IMI should be confirmed by bacteriology (NMC, 2012). Additional between-study variation could be a result of differing definitions of IMI, as Dohoo et al. (2011b) showed by comparing the number of colonies isolated, presence of an organism in pure or mixed culture, and evaluation of SCC. Variation in definitions of IMI becomes increasingly complex with the use of different tests, such as SCC, California Mastitis Test, electrical conductivity, or $\mathrm{pH}$, and the 
selection of thresholds within those tests (Tiwari et al., 2018). Limiting the variation in methodology would additionally be beneficial to removing variance in effect, to further aid evidence-based decision-making.

\section{Limitations of this Review}

Articles published before 1990 were excluded from the search strategy and thus were not included in this scoping review. Although genetic selection for superior milk production (USDA, 2004; Dobson et al., 2007; Barkema et al., 2015) and major advances in disease prevention have occurred in recent decades (LeBlanc et al., 2006), and as a result, the effects of DO management practices are likely different in these modern populations compared with those of several decades ago, the cut-point is arbitrary. However, the purpose of this scoping review was to provide a summary of a broad range of literature, with the potential of informing future quantitative synthesis on narrower aspects of DO management. Future quantitative synthesis in one of the areas captured by our review may opt to include metaregression by year of trial conduct, to further elucidate whether the impact of the given management practices differs as the dairy cattle population has changed over time.

Fifty-one articles were not able to be accessed via full text by librarians. These articles may have contributed further evidence within our scoping review. However, the 229 articles included in this review provide a basis for future synthesis work into areas of management such as vaccines, dry period length, and nutrition, which includes ration formulation and delivery and vitamin and mineral feed additives.

Based on the resources available, 224 articles were excluded before full-text screening because they were not available in English (Figure 1). The 224 articles were published in 27 different languages, which included Arabic, Chinese, Croatian, Czech, Danish, Dutch, French, German, Hungarian, Italian, Japanese, Korean, Lithuanian, Macedonian, Norwegian, Persian, Polish, Portuguese, Russian, Serbian, Serbo-Croatian, Slovakian, Slovenian, Spanish, Swedish, Thai, and Turkish. Although these articles may have added relevant information, the body of literature encompassed in this review informs the utility of a systematic literature review and meta-analysis on the efficacy of management practices to improve udder health postcalving, specifically for nutrition, dry period length, and vaccines. Further, fewer than half of the articles in this scoping review were from Canada or the United States, indicating that literature outside of North America was well represented.

\section{CONCLUSIONS}

Ten groups of management practices identified as strategies implemented at drying off that improve udder health postcalving were formed. Nutrition, which included ration formulation and delivery and vitamin and mineral feed supplements, was the most common type of management strategy, followed by vaccination and dry period length. The use of systematic review and meta-analysis methods to target these areas of dry cow management, and to quantify their role in prevention and cure of IMI and CM, may be useful to compare these management strategies against antimicrobial or teat sealant interventions. Areas with few available research articles, such as bovine somatotropin injections, and intramammary and intramuscular injections of nonantimicrobial remedies, could benefit from additional primary research studies to add evidence to their effects on dry cow health. In addition, relevant outcomes, such as CM, cure, prevention, and prevalence of IMI, and measurement of SCC, were widely considered; however, we found large variation in the risk periods considered for each outcome. Organizations focusing on udder health in the dairy industry could form consensus statements regarding optimal follow-up periods that should be used in mastitis research to decrease the variability in the measurement of outcomes and risk period selection.

\section{ACKNOWLEDGMENTS}

There was no external funding support for this scoping review. Stipend funding support for CKM was provided by the OVC Entrance Award and the Queen Elizabeth II Graduate Scholarship in Science and Technology from the University of Guelph and the Ministry of Training, Colleges and Universities. Additional acknowledgements are given to the donors of the Dr. Francis H. S. Newbould Award, the Dr. Casey Buizert Memorial Award, the Dr. R. A. McIntosh Graduate Award (OVC '45), and the Barbara Kell Gonsalves Memorial Scholarship for their funding support. CKM developed the review protocol, coordinated the research teams, developed the search strategy, conducted all searches, created data screening and data extraction tools, conducted data screening and data extraction, conducted data characterization, interpreted the results, and developed the manuscript drafts. JMS, DFK, and CBW provided methodological support and content expertise, commented on manuscript drafts, and approved the final manuscript. KSC and KJC conducted data screening and data extraction, commented on manuscript drafts, and approved the 
final manuscript. None of the authors have conflicts of interest to declare.

\section{REFERENCES}

Arksey, H., and L. O'Malley. 2005. Scoping studies: Towards a methodological framework. Int. J. Soc. Res. 8:19-32. https://doi.org/10 $.1080 / 1364557032000119616$.

Arruda, A. G., S. Godden, P. Rapnicki, P. Gorden, L. Timms, S. S. Aly, T. W. Lehenbauer, and J. Champagne. 2013. Randomized noninferiority clinical trial evaluating 3 commercial dry cow mastitis preparations: I. Quarter-level outcomes. J. Dairy Sci. 96:44194435. https://doi.org/10.3168/jds.2012-6461.

Barkema, H. W., M. A. G. von Keyserlingk, J. P. Kastelic, T. J. G. M. Lam, C. Luby, J.-P. Roy, S. J. LeBlanc, G. P. Keefe, and D. F. Kelton. 2015. Invited review: Changes in the dairy industry affecting dairy cattle health and welfare. J. Dairy Sci. 98:7426-7445. https://doi.org/10.3168/jds.2015-9377.

Berry, E. A., and J. E. Hillerton. 2002. The effect of an intramammary teat seal on new intramammary infections. J. Dairy Sci. 85:25122520. https://doi.org/10.3168/jds.S0022-0302(02)74334-8.

Berry, E. A., and J. E. Hillerton. 2007. Effect of an intramammary teat seal and dry cow antibiotic in relation to dry period length on postpartum mastitis. J. Dairy Sci. 90:760-765. https://doi.org/10 .3168/jds.S0022-0302(07)71560-6.

Bradley, A. J., and M. J. Green. 2000. A study of the incidence and significance of intramammary enterobacterial infections acquired during the dry period. J. Dairy Sci. 83:1957-1965. https://doi.org/ 10.3168/jds.S0022-0302(00)75072-7.

Bradley, A. J., and M. J. Green. 2001. An investigation of the impact of intramammary antibiotic dry cow therapy on clinical coliform mastitis. J. Dairy Sci. 84:1632-1639. https://doi.org/10.3168/jds .s0022-0302(01)74598-5.

Cameron, M., G. P. Keefe, J. P. Roy, H. Stryhn, I. R. Dohoo, and S. L. McKenna. 2015. Evaluation of selective dry cow treatment following on-farm culture: Milk yield and somatic cell count in the subsequent lactation. J. Dairy Sci. 98:2427-2436. https://doi.org/ $10.3168 /$ jds.2014-8876.

Church, G. T., L. K. Fox, C. T. Gaskins, D. D. Hancock, and J. M. Gay. 2008. The effect of a shortened dry period on intramammary infections during the subsequent lactation. J. Dairy Sci. 91:42194225. https://doi.org/10.3168/jds.2008-1377.

Dingwell, R. T., D. F. Kelton, and K. E. Leslie. 2003a. Management of the dry cow in control of peripartum disease and mastitis. Vet. Clin. North Am. Food Anim. Pract. 19:235-265. https://doi.org/ 10.1016/S0749-0720(02)00072-5.

Dingwell, R. T., K. E. Leslie, T. F. Duffield, Y. H. Schukken, L. DesCoteaux, G. P. Keefe, D. F. Kelton, K. D. Lissemore, W. Shewfelt, P. Dick, and R. Bagg. 2003b. Efficacy of intramammary tilmicosin and risk factors for cure of Staphylococcus aureus infection in the dry period. J. Dairy Sci. 86:159-168. https://doi.org/10.3168/jds .S0022-0302(03)73596-6.

Dingwell, R. T., K. E. Leslie, J. M. Sargeant, Y. H. Schukken, L. L. Timms, and J. E. Shirley. 2002. Evaluation of the California Mastitis Test to determine udder health status of early lactation dairy cows. Kansas Agricultural Experiment Station Research Reports. 0:11-14. https://doi.org/10.4148/2378-5977.3149.

Dobson, H., R. F. Smith, M. D. Royal, C. H. Knight, and I. M. Sheldon. 2007. The high producing dairy cow and its reproductive performance. Reprod. Domest. Anim. 42(Suppl. 2):17-23. https:// doi.org/10.1111/j.1439-0531.2007.00906.x.

Dohoo, I., S. Andersen, R. Dingwell, K. Hand, D. Kelton, K. Leslie, Y. Schukken, and S. Godden. 2011a. Diagnosing intramammary infections: Comparison of multiple versus single quarter milk samples for the identification of intramammary infections in lactating dairy cows. J. Dairy Sci. 94:5515-5522. https://doi.org/10.3168/jds.2011 -4486 .

Dohoo, I. R., J. Smith, S. Andersen, D. F. Kelton, and S. Godden. 2011b. Diagnosing intramammary infections: Evaluation of defi- nitions based on a single milk sample. J. Dairy Sci. 94:250-261. https://doi.org/10.3168/jds.2010-3559.

Down, P. M., A. J. Bradley, J. E. Breen, W. J. Browne, T. Kypraios, and M. J. Green. 2016. A Bayesian micro-simulation to evaluate the cost-effectiveness of interventions for mastitis control during the dry period in UK dairy herds. Prev. Vet. Med. 133:64-72. https://doi.org/10.1016/j.prevetmed.2016.09.012.

Dufour, S., A. Fréchette, H. W. Barkema, A. Mussell, and D. T. Scholl. 2011. Invited review: Effect of udder health management practices on herd somatic cell count. J. Dairy Sci. 94:563-579. https://doi .org/10.3168/jds.2010-3715.

Dufour, S., V. Wellemans, J.-P. Roy, P. Lacasse, A. Ordonez-Iturriaga, and D. Francoz. 2019. Non-antimicrobial approaches at drying-off for treating and preventing intramammary infections in dairy cows. Part 1. Meta-analyses of efficacy of using an internal teat sealant without a concomitant antimicrobial treatment. Anim. Health Res. Rev. 20:86-97. https://doi.org/10.1017/S1466252319000070.

Godden, S., P. Rapnicki, S. Stewart, J. Fetrow, A. Johnson, R. Bey, and R. Farnsworth. 2003. Effectiveness of an internal teat seal in the prevention of new intramammary infections during the dry and early-lactation periods in dairy cows when used with a dry cow intramammary antibiotic. J. Dairy Sci. 86:3899-3911. https://doi .org/10.3168/jds.S0022-0302(03)73998-8.

Gott, P. N., P. J. Rajala-Schultz, G. M. Schuenemann, K. L. Proudfoot, and J. S. Hogan. 2016. Intramammary infections and milk leakage following gradual or abrupt cessation of milking. J. Dairy Sci. 99:4005-4017. https://doi.org/10.3168/jds.2015-10348.

Gott, P. N., P. J. Rajala-Schultz, G. M. Schuenemann, K. L. Proudfoot, and J. S. Hogan. 2017. Effect of gradual or abrupt cessation of milking at dry off on milk yield and somatic cell score in the subsequent lactation. J. Dairy Sci. 100:2080-2089. https://doi .org/10.3168/jds.2016-11444.

Green, M. J., A. J. Bradley, G. F. Medley, and W. J. Browne. 2007. Cow, farm, and management factors during the dry period that determine the rate of clinical mastitis after calving. J. Dairy Sci. 90:3764-3776. https://doi.org/10.3168/jds.2007-0107.

Halasa, T., M. Nielen, A. C. Whist, and O. Østerås. 2009a. Metaanalysis of dry cow management for dairy cattle. Part 2. Cure of existing intramammary infections. J. Dairy Sci. 92:3150-3157. https://doi.org/10.3168/jds.2008-1741.

Halasa, T., O. Østerås, H. Hogeveen, T. van Werven, and M. Nielen. 2009b. Meta-analysis of dry cow management for dairy cattle. Part 1. Protection against new intramammary infections. J. Dairy Sci 92:3134-3149. https://doi.org/10.3168/jds.2008-1740.

Kirkham, J. J., S. Gorst, D. G. Altman, J. M. Blazeby, M. Clarke, S. Tunis, P. R. Williamson, and COS-STAP Group. 2019. Core Outcome Set-STAndardised Protocol Items: The COS-STAP Statement. Trials 20:116-7. https://doi.org/10.1186/s13063-019-3230 $-\mathrm{x}$.

Lam, T. J. G. M., R. G. M. Olde Riekerink, O. C. Sampimon, and H. Smith. 2009. Mastitis diagnostics and performance monitoring: a practical approach. Ir. Vet. J. 62(Suppl. 4):S34-S39. https://doi .org/10.1186/2046-0481-62-S4-S34.

Lean, I. J., J. E. P. Santos, E. Block, and H. M. Golder. 2019. Effects of prepartum dietary cation-anion difference intake on production and health of dairy cows: A meta-analysis. J. Dairy Sci. 102:21032133. https://doi.org/10.3168/jds.2018-14769.

LeBlanc, S. J., K. D. Lissemore, D. F. Kelton, T. F. Duffield, and K. E. Leslie. 2006. Major advances in disease prevention in dairy cattle. J. Dairy Sci. 89:1267-1279. https://doi.org/10.3168/jds.S0022 $-0302(06) 72195-6$

Leitner, G., S. Jacoby, and N. Silanikove. 2011. An evaluation of casein hydrolyzate in combination with antibiotic for bacterial cure and subsequent increase in milk yield in dairy cows. BMC Vet. Res. 7:3. https://doi.org/10.1186/1746-6148-7-3.

Liberati, A., D. G. Altman, J. Tetzlaff, C. Mulrow, P. C. Gøtzsche, J. P. A. Ioannidis, M. Clarke, P. J. Devereaux, J. Kleijnen, and D. Moher. 2009. The PRISMA statement for reporting of systematic reviews and meta-analyses of studies that evaluate health care interventions: explanation and elaboration. PLoS Med. 6:e1000100. https://doi.org/10.1371/journal.pmed.1000100. 
McMullen, C. K., J. M. Sargeant, D. F. Kelton, K. J. Churchill, K. S. Cousins, and C. B. Winder. 2021. Supplementary data for: Modifiable management practices to improve udder health in dairy cattle during the dry period and early lactation: A scoping review [dataset]. Scholars Portal Dataverse. https://doi.org/10.5683/SP2/ TJVYOZ.

Middleton, J. R., and L. K. Fox. 1999. A comparison of betadine and chlorhexidine for drying-off mammary quarters chronically infected with Staphylococcus aureus. Pages 213-214 in Natl. Mastitis Counc. 38th Ann. Mtg. Proc., Natl. Mastitis Counc. Inc., Madison, WI.

Moghimi-Kandelousi, M. H., A. A. Alamouti, M. Imani, and Q. Zebeli. 2020. A meta-analysis and meta-regression of the effects of vitamin E supplementation on serum enrichment, udder health, milk yield, and reproductive performance of transition cows. J. Dairy Sci. 103:6157-6166. https://doi.org/10.3168/jds.2019-17556.

Moher, D., A. Liberati, J. Tetzlaff, D. G. Altman, and The PRISMA Group. 2009. Preferred Reporting Items for Systematic Reviews and Meta-Analyses: The PRISMA statement. PLoS Med. 6:e1000097. https://doi.org/10.1371/journal.pmed.1000097.

Mullen, K. A. E., K. L. Anderson, and S. P. Washburn. 2014. Effect of 2 herbal intramammary products on milk quantity and quality compared with conventional and no dry cow therapy. J. Dairy Sci. 97:3509-3522. https://doi.org/10.3168/jds.2013-7460.

Naqvi, S. A., D. B. Nobrega, P. E. Ronksley, and H. W. Barkema. 2018. Invited review: Effectiveness of precalving treatment on postcalving udder health in nulliparous dairy heifers: A systematic review and meta-analysis. J. Dairy Sci. 101:4707-4728. https://doi .org/10.3168/jds.2017-14301.

National Mastitis Council (NMC). 2004. Procedures for collecting milk samples. Accessed Aug. 4, 2020. https://www.nmconline .org/wp-content/uploads/2016/09/Procedures-for-Collecting-Milk -Samples.pdf.

National Mastitis Council (NMC). 2012. Interpreting bacteriological culture results to diagnose bovine intramammary infections. Accessed Aug. 4, 2020. https://www.nmconline.org/wp-content/ uploads/2016/08/Interpreting-Bacteriological-Culture-Results .pdf.

Newman, K. A., P. J. Rajala-Schultz, F. J. DeGraves, and J. Lakritz. 2010. Association of milk yield and infections status at dry-off with intramammary infections at subsequent calving. J. Dairy Res. 77:99-106. https://doi.org/10.1017/S0022029909990380.

O'Connor, A. M., and J. M. Sargeant. 2014. Meta-analyses including data from observational studies. Prev. Vet. Med. 113:313-322. https://doi.org/10.1016/j.prevetmed.2013.10.017 https://doi.org/ https://doi-org.subzero.lib.uoguelph.ca/10.1016/j.prevetmed.2013 10.017 .

O'Connor, A. M., J. M. Sargeant, I. A. Gardner, J. S. Dickson, M. E. Torrence, C. E. Dewey, I. R. Dohoo, R. B. Evans, J. T. Gray, M. Greiner, G. Keefe, S. L. Lefebvre, P. S. Morley, A. Ramirez, W. Sischo, D. R. Smith, K. Snedeker, J. Sofos, M. P. Ward, and R. Wills. 2010. The REFLECT statement: Methods and processes of creating reporting guidelines for randomized controlled trials for livestock and food safety. Prev. Vet. Med. 93:11-18. https://doi .org/10.1016/j.prevetmed.2009.10.008.

Odensten, M. O., B. Berglund, K. P. Waller, and K. Holtenius. 2007a. Metabolism and udder health at dry-off in cows of different breeds and production levels. J. Dairy Sci. 90:1417-1428. https://doi.org/ 10.3168/jds.S0022-0302(07)71627-2.

Odensten, M. O., K. Holtenius, and K. P. Waller. 2007b. Effects of two different feeding strategies during dry-off on certain health aspects of dairy cows. J. Dairy Sci. 90:898-907. https://doi.org/10.3168/ jds.S0022-0302(07)71573-4.

Pantoja, J. C. F., C. Hulland, and P. L. Ruegg. 2009. Somatic cell count status across the dry period as a risk factor for the development of clinical mastitis in the subsequent lactation. J. Dairy Sci. 92:139-148. https://doi.org/10.3168/jds.2008-1477.

Rabiee, A. R., and I. J. Lean. 2013. The effect of internal teat sealant products (Teatseal and Orbeseal) on intramammary infection, clinical mastitis, and somatic cell counts in lactating dairy cows:
A meta-analysis. J. Dairy Sci. 96:6915-6931. https://doi.org/10 $.3168 /$ jds.2013-6544.

Rajala-Schultz, P. J., J. S. Hogan, and K. L. Smith. 2005. Short communication: Association between milk yield at dry-off and probability of intramammary infections at calving. J. Dairy Sci. 88:577-579. https://doi.org/10.3168/jds.S0022-0302(05)72720-X.

Rajala-Schultz, P. J., A. H. Torres, and F. J. Degraves. 2011. Milk yield and somatic cell count during the following lactation after selective treatment of cows at dry off. J. Dairy Res. 78:489-499. https://doi.org/10.1017/S0022029911000690.

Santos, J. E. P., I. J. Lean, H. Golder, and E. Block. 2019. Meta-analysis of the effects of prepartum dietary cation-anion difference on performance and health of dairy cows. J. Dairy Sci. 102:2134-2154. https://doi.org/10.3168/jds.2018-14628.

Sargeant, J. M., K. E. Leslie, J. E. Shirley, B. J. Pulkrabek, and G. H. Lim. 2001. Sensitivity and specificity of somatic cell count and California Mastitis Test for identifying intramammary infection in early lactation. J. Dairy Sci. 84:2018-2024. https://doi.org/10 .3168/jds.S0022-0302(01)74645-0.

Sargeant, J. M., and A. M. O'Connor. 2014. Introduction to systematic reviews in animal agriculture and veterinary medicine. Zoonoses Public Health 61:3-9. https://doi.org/10.1111/zph.12128.

Sargeant, J. M., A. M. O'Connor, I. R. Dohoo, H. N. Erb, M. Cevallos, M. Egger, A. K. Ersboll, S. W. Martin, L. R. Nielsen, D. L. Pearl, D. U. Pfeiffer, J. Sanchez, M. E. Torrence, H. Vigre, C. Waldner, and M. P. Ward. 2016. Methods and processes of developing the strengthening the reporting of observational studies in epidemiology - veterinary (STROBE-Vet) statement. Prev. Vet. Med. 134:188-196. https://doi.org/10.1016/j.prevetmed.2016.09.005.

Sargeant, J. M., A. M. O'Connor, I. A. Gardner, J. S. Dickson, M. E. Torrence, I. R. Dohoo, S. L. LeFebvre, P. S. Morley, A. Ramirez, and K. Snedeker. 2010. The REFLECT statement: Reporting guidelines for randomized controlled trials in livestock and food safety: Explanation and elaboration. J. Food Prot. 73:579-603. https://doi.org/10.4315/0362-028X-73.3.579.

Sargeant, J. M., A. M. O'Connor, and C. B. Winder. 2019. Editorial: Systematic reviews reveal a need for more, better data to inform antimicrobial stewardship practices in animal agriculture. Anim. Health Res. Rev. 20:103-105. https://doi.org/10.1017/ S1466252319000240.

Schukken, Y. H., J. Vanvliet, D. Vandegeer, and F. J. Grommers. 1993. A randomized blind trial on dry cow antibiotic infusion in a low somatic cell count herd. J. Dairy Sci. 76:2925-2930. https:// doi.org/10.3168/jds.S0022-0302(93)77632-8.

Shirley, D. A., and M. A. McArthur. 2011. The utility of human challenge studies in vaccine development: lessons learned from cholera. Vaccine (Auckl.) 2011:3-13. https://doi.org/10.2147/VDT .S23634.

Tiwari, S., T. K. Mohanty, T. K. Patbandha, A. Kumaresan, M. Bhakat, N. Kumar, and R. K. Baithalu. 2018. Critical threshold of milk SCC, $\mathrm{EC}$ and $\mathrm{pH}$ for detection of sub-clinical mastitis in crossbred cows reared under subtropical agroclimatic condition. Int. J. Livest. Res. 8:152-159. https://doi.org/10.5455/ijlr .20170620120712 .

Tricco, A. C., E. Lillie, W. Zarin, K. K. O'Brien, H. Colquhoun, D. Levac, D. Moher, M. D. Peters, T. Horsley, L. Weeks, S. Hempel, E. A. Akl, C. Chang, J. McGowan, L. Stewart, L. Hartling, A. Aldcroft, M. G. Wilson, C. GarritTy, S. Lewin, C. M. Godfrey, M. T. Macdonald, E. V. Langlois, K. Soares-Weiser, J. Moriarty, T. Clifford, O. Tunçalp, and S. E. Straus. 2018. PRISMA extension for scoping reviews (PRISMA-ScR): Checklist and explanation. Ann. Intern. Med. 169:467-473. https://doi.org/10.7326/M18-0850.

Tucker, C. B., S. J. Lacy-Hulbert, and J. R. Webster. 2009. Effect of milking frequency and feeding level before and after dry off on dairy cattle behavior and udder characteristics. J. Dairy Sci. 92:3194-3203. https://doi.org/10.3168/jds.2008-1930.

U.S. Food and Drug Administration (FDA). 2020. Bovine somatotropin (bST). Accessed Aug. 19, 2020. https://www.fda.gov/animal -veterinary/product-safety-information/bovine-somatotropin-bst. 
USDA. 2004. The changing landscape of U.S. milk production. Accessed Feb. 2, 2021. https://ageconsearch.umn.edu/record/ 262277/ \#record-files-collapse-header.

van Knegsel, A. T. M., S. G. A. van der Drift, J. Cermáková, and B. Kemp. 2013. Effects of shortening the dry period of dairy cows on milk production, energy balance, health, and fertility: A systematic review. Vet. J. 198:707-713. https://doi.org/10.1016/j.tvjl .2013 .10 .005

Vilar, M. J., and P. J. Rajala-Schultz. 2020. Dry-off and dairy cow udder health and welfare: Effects of different milk cessation methods. Vet. J. 262:105503. https://doi.org/10.1016/j.tvjl.2020.105503.

Winder, C. B., J. M. Sargeant, D. Hu, C. Wang, D. F. Kelton, S. LeBlanc, T. F. Duffield, J. Glanville, H. Wood, K. J. Churchill, J. Dunn, M. D. Bergevin, K. Dawkins, S. Meadows, B. Deb, M. Reist, C. Moody, and A. M. O'Connor. 2019a. Comparative efficacy of antimicrobial treatments in dairy cows at dry-off to prevent new intramammary infections during the dry period or clinical mastitis during early lactation: a systematic review and network metaanalysis. Anim. Health Res. Rev. 20:199-216. https://doi.org/10 $1017 /$ S1466252319000239.

Winder, C. B., J. M. Sargeant, D. Hu, C. Wang, D. F. Kelton, S. LeBlanc, T. F. Duffield, J. Glanville, H. Wood, K. J. Churchill, J. Dunn, M. D. Bergevin, K. Dawkins, S. Meadows, B. Deb, M. Reist, C. Moody, and A. M. O'Connor. 2019b. Comparative efficacy of teat sealants given prepartum for prevention of intramammary infections and clinical mastitis: A systematic review and network meta-analysis. Anim. Health Res. Rev. 20:182-198. https://doi .org/10.1017/S1466252319000276.

World Organisation for Animal Health. 2019. OIE list of antimicrobial agents of veterinary importance. Accessed Aug. 4, 2020. https:// www.oie.int/fileadmin/Home/eng/Our_scientific_expertise/docs/ pdf/AMR/A_OIE_List_antimicrobials_July2019.pdf.

Zobel, G., K. Leslie, D. M. Weary, and M. A. von Keyserlingk. 2013. Gradual cessation of milking reduces milk leakage and motivation to be milked in dairy cows at dry-off. J. Dairy Sci. 96:5064-5071. https://doi.org/10.3168/jds.2012-6501.

Zobel, G., D. M. Weary, K. E. Leslie, and M. A. G. von Keyserlingk. 2015. Invited review: Cessation of lactation: effects on animal welfare. J. Dairy Sci. 98:8263-8277. https://doi.org/10.3168/jds.2015 $-9617$.

\section{ORCIDS}

Carrie K. McMullen @ https://orcid.org/0000-0003-1141-3217

Jan M. Sargeant (ㄴ) https://orcid.org/0000-0003-2420-1766

David F. Kelton () https://orcid.org/0000-0001-9606-7602

Katheryn J. Churchill @ https://orcid.org/0000-0002-8767-3181

Kineta S. Cousins @ \. https://orcid.org/0000-0002-8704-0878

Charlotte B. Winder ๑ https://orcid.org/0000-0002-7314-3657 